\title{
The authors reply:
}

We thank Labeau et al (1) for their interest and thoughtful letter about our systematic review of the incidence and prevalence of pressure injuries (PIs) in adult ICU patients (2), recently published article in Critical Care Medicine. We agree heterogeneity was the major threat to validity in pooling the ICU incidence and prevalence and we also agree on the potential sources of heterogeneity. As Labeau et al (1) note, it was not possible to assess most potential causes of het-erogeneity in ICU PI events due to paucity of data, which we too identified. The influence of nurses' workload on PI occurrence is an inconclusive area. One study cited in a review noted that increased ICU nurse staffing in was associated with decreased PI development (3). Internationally, the intensive care environment remains a comparatively well-resourced clinical area. Although we argue adequate staffing levels are important for the prevention of $\mathrm{PI}$, timely regular skin assessment and implementation of prevention strategies based on patient need also strongly influence the outcome of PI development. Because of ICU patients' disease acuity and complexity, emerging evidence to suggest multicomponent PI prevention programs, especially those with multidisciplinary involvements, are needed (46). We too believe PI prevention requires a multidisciplinary approach.

We had also postulated that a country's wealth, classified as low-, middle-, or high-income countries (according to Gross Domestic Product [GDP]) may serve as a proxy for the quality of overall healthcare provision. But, our quick analysis showed no clear patterns in the data by GDP, perhaps because a myriad of other factors influence the development of PI beyond simply being in a rich or poor country. Some of these confounding factors were well articulated by Labeau et al (1). We too believe PI prevention requires a multidisciplinary approach. We think the international DecubICUs study may provide valuable insights into numerous factors that influence prevalence of $\mathrm{PI}$ in the ICU setting. In the meantime, our team plans to continue further research synthesis studies to better understand PI in the ICU setting.

Dr. Coyer's institution received funding from 3M and Molnlycke Pty Ltd. The remaining authors have disclosed that they do not have any potential conflicts of interest.

Wendy P. Chaboyer, PhD, FACCCN, FAAN, School of Nursing and Midwifery, Menzies Health Institute Queensland, Griffith University, QLD, Australia;

Lukman Thalib, PhD, Department of Public Health, College of Health Sciences, Qatar University, Doha, Qatar; Emma L. Harbeck, PhD, Menzies Health Institute Queensland, Griffith University, QLD, Australia;

Fiona M. Coyer, PhD, Intensive Care Services, Royal Brisbane and Women's Hospital and School of Nursing, Queensland University of Technology, Brisbane, QLD, Australia, and Institute for Skin Integrity and Infection Prevention, University of Huddersfield, Huddersfield, United Kingdom;

Stijn Blot, PhD, Department of Internal Medicine, Ghent University, Ghent, Belgium, and Burns, Trauma and Critical Care Research Centre, University of Queensland Centre for Clinical Research, Faculty of Medicine, The University of Queensland, Brisbane, QLD, Australia;

Claudia F. Bull, BNutr(Hon), Menzies Health Institute Queensland, Griffith University, QLD, Australia ; 
Paula C. Nogueira, PhD, Department of Medical-Surgical Nursing, School of Nursing, University of Saõ Paulo, Saõ Paulo, Brazil;

Frances F. Lin, PhD, School of Nursing and Midwifery, Menzies Health Institute Queensland, Griffith University, QLD, Australia

\section{REFERENCES}

1. Labeau SO, Afonso EP, Llaurado-Serra M: Pressure Injury Research in the ICU: Getting Rid of a Black Spot. Crit Care Med 2019; 47:e161-e162

2. Chaboyer WP, Thalib L, Harbeck EL, et al: Incidence and preva-lence of pressure injuries in adult intensive care patients: A sys- tematic review and meta-analysis. Crit Care Med 2018; 46: e1074e1081

3. McGahan M, Kucharski G, Coyer F; Winner ACCCN Best Nursing Review Paper 2011 sponsored by Elsevier: Nurse staffing levels and the incidence of mortality and morbidity in the adult intensive care unit: $A$ literature review. Aust Crit Care 2012; 25:64-77

4. Coyer F, Gardner A, Doubrovsky A, et al: Reducing pressure injuries in critically ill patients by using a patient skin integrity care bundle (InSPiRE). Am J Crit Care 2015; 24:199-209

5. Donovan EA, Manta CJ, Goldsack JC, et al: Using a lean six sigma approach to yield sustained pressure ulcer prevention for complex critical care patients. J Nurs Adm 2016; 46:43-48

6. Llaurado-Serra M, Afonso E: Pressure injuries in intensive care: What is new? Intensive Crit Care Nurs 2018; 45:3-5 